7th International Symposium on Superalloy 718 and Derivatives Edited by: E.A. Ott, J.R. Groh, A. Banik, I. Dempster, T.P. Gabb, R. Helmink, X. Liu, A. Mitchell, G.P. Sjöberg, and A. Wusatowska-Sarnek TMS (The Minerals, Metals \& Materials Society), 2010

\title{
On the influence of temperature on the hydrogen embrittlement susceptibility of alloy 718
}

\author{
Florian Galliano $^{1}$, Benoit Ter-Ovanessian ${ }^{1,2}$, Eric Andrieu ${ }^{1}$, Jean-Marc Cloué2 \\ Christine Baret-Blanc ${ }^{1}$, Grégory Odemer ${ }^{1}$ \\ ${ }^{1}$ Université de Toulouse, CIRIMAT, UPS/CNRS/INPT, \\ 4 Allée Emile Monso, 31432 Toulouse Cedex 4, France \\ ${ }^{2}$ AREVA NP \\ 10 rue Juliette Récamier, 69456 Lyon Cedex 6, France
}

Keywords: alloy 718, strengthening phases, hydrogen embrittlement, hydrogen trapping

\begin{abstract}
Hydrogen is susceptible to modify mechanisms of stress corrosion cracking of alloy 718 component structure elements in Pressurized Water Reactors (PWR), during service at temperatures from $80^{\circ} \mathrm{C}$ to $340^{\circ} \mathrm{C}$. In order to study hydrogen embrittlement susceptibility of alloy 718, samples have been firstly cathodically charged in hydrogen in molten salts $\left(\mathrm{NaHSO}_{4}\right.$, $46.5 \%$ wt. $-\mathrm{KHSO}_{4}, 53.5 \%$ wt.) at $150^{\circ} \mathrm{C}$. After charging, tensile tests were carried out at $80^{\circ} \mathrm{C}$, $150^{\circ} \mathrm{C}$ and $300^{\circ} \mathrm{C}$ for a constant strain rate of $5 \times 10^{-4} \mathrm{~s}^{-1}$. Quantification of hydrogen embrittlement was performed by the analysis of rupture modes and elongation to failure. Rupture mode identification and tensile tests evidenced a maximal susceptibility to hydrogen embrittlement at $80^{\circ} \mathrm{C}$ whereas hydrogen effect was less noticeable at $300^{\circ} \mathrm{C}$. From these results, the evolution of hydrogen location and interaction with deformation as a function of temperature was then discussed.
\end{abstract}

\section{Introduction}

Alloy 718 is a Ni-based superalloy in which austenitic $\gamma$ matrix solid solution is reinforced by $\gamma^{\prime}$ $\left(\mathrm{Ni}_{3} \mathrm{Al}\right)$ and $\gamma$ ' $\left(\mathrm{Ni}_{3} \mathrm{Nb}\right)$ precipitates. It is widely used to manufacture structural components for aeronautic applications as well as in nuclear applications. When alloy 718 is used at high temperature, hydrogen embrittlement has not been mentioned. On the contrary, industrial applications involving service temperatures ranging from room temperature up to $400^{\circ} \mathrm{C}$ are susceptible to be affected by hydrogen embrittlement. For instance, it has been reported that stress corrosion cracking (SCC) at working or handling temperature, respectively $300^{\circ} \mathrm{C}$ and $80^{\circ} \mathrm{C}$, can involve hydrogen embrittlement mechanisms. [1-4]. Thereby mechanical behaviour of alloy 718 under hydrogenating conditions was often studied in this temperature range. Nevertheless, due to heat effect and fabrication history i.e. metallurgical state, the susceptibility to hydrogen embrittlement (HE) has to be assessed even if a few data exist in this temperature range [5,12]. It is worth mentioning that Symons for X-750 alloy [8] and Wei [5] for alloy 718, have shown an effect of hydrogen on the mechanical behaviour of the corresponding alloys at $300^{\circ} \mathrm{C}$ that suggests that $\mathrm{HE}$ must be considered at high temperatures. 
The present study aims to quantify hydrogen embrittlement susceptibility of alloy 718 in the temperature range of $25^{\circ} \mathrm{C}-300^{\circ} \mathrm{C}$ using both an analysis of the evolution of fracture surfaces of hydrogenated specimens with temperature and an assessment of the modification of the true uniform strain.

$\underline{\text { Material }}$

\section{Experimental procedure}

Experiments were conducted on a $0.5 \mathrm{~mm}$ thick annealed thin sheet of alloy 718 provided by Areva NP. The standard chemical composition of alloy 718 is given in Table 1. Flat tensile specimens with one of the two "shoulders" longer than the other one were machined in the thin sheet for mechanical tests. This tensile specimen geometry allowed coupons of material to be removed for additional analyses on the tensile specimens. Before charging, the specimens were conventionally heat treated at $720^{\circ} \mathrm{C} / 8 \mathrm{~h}$, furnace cooled at $55^{\circ} \mathrm{C} / \mathrm{h}$, then maintained at $620^{\circ} \mathrm{C} / 8 \mathrm{~h}$ in vacuum and finally furnace cooled. Metallographic study revealed a microstructure with an average grain size of $12 \mu \mathrm{m}$ (Fig. 1).

\begin{tabular}{|c|c|c|c|c|c|c|c|c|c|c|c|c|c|c|c|}
\hline & $\mathrm{Fe}$ & $\mathrm{Ni}$ & $\mathrm{Cr}$ & $\mathrm{Nb}+\mathrm{Ta}$ & $\mathrm{Mo}$ & $\mathrm{Ti}$ & $\mathrm{Al}$ & $\mathrm{Mn}$ & $\mathrm{Si}$ & $\mathrm{Cu}$ & $\mathrm{Co}$ & $\mathrm{C}$ & $\mathrm{P}$ & $\mathrm{S}$ & $\mathrm{B}$ \\
\hline Min & Bal. & 50 & 17 & 4.75 & 2.8 & 0.65 & 0.2 & - & - & - & - & - & - & - & - \\
\hline Max & Bal. & 55 & 21 & 5.5 & 3.3 & 1.15 & 0.8 & 0.35 & 0.35 & 0.3 & 0.1 & 0.08 & 0.015 & 0.015 & 0.006 \\
\hline
\end{tabular}

Table 1: Standard chemical compositions (wt \%) of alloy 718

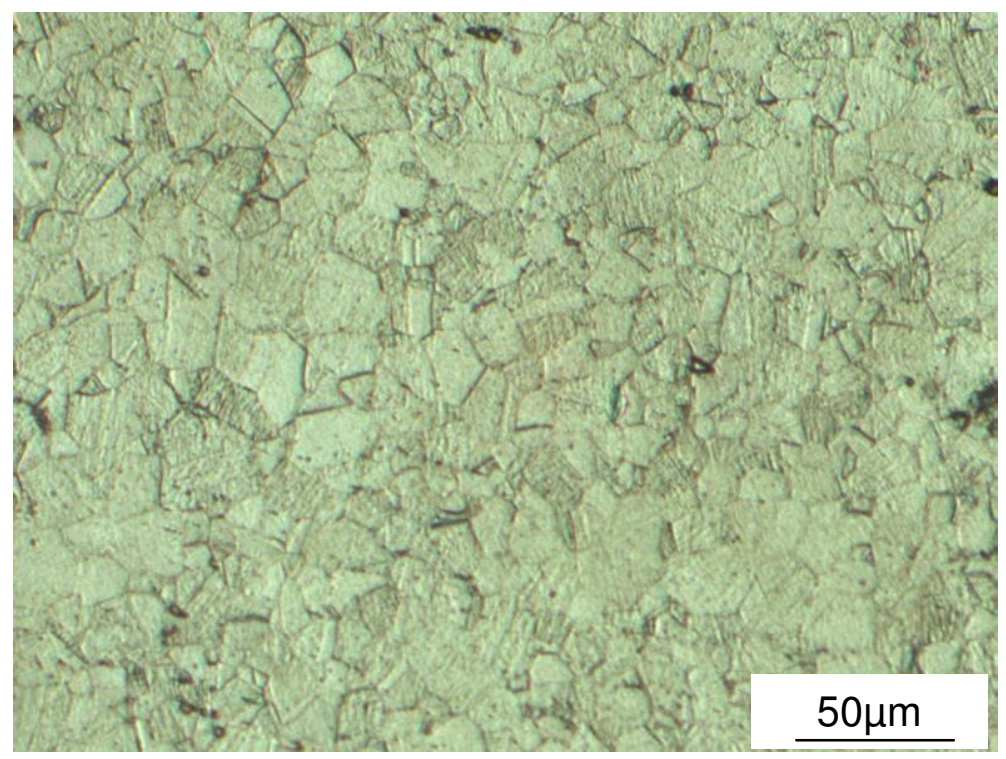

Fig. 1: Microstructure of studied alloy 718

Hydrogen charging method

Assuming that the diffusion rate of hydrogen is very low in Ni-based alloys at room temperature (RT) $\left(4.5 \times 10^{-11} \mathrm{~cm}^{2} \cdot \mathrm{s}^{-1}<\mathrm{D}<9.5 \times 10^{-11} \mathrm{~cm}^{2} \cdot \mathrm{s}^{-1}\right)$ [9], hydrogen was introduced into the flat tensile specimens at $150^{\circ} \mathrm{C}$ by cathodic charging in an eutectic mixture of molten salts $\left(\mathrm{NaHSO}_{4}, \mathrm{H}_{2} \mathrm{O}\right.$ $53.5 \%-\mathrm{KHSO}_{4} 46.5 \%$ ) [10]. A cathodic potential of $-1000 \mathrm{mV} / \mathrm{Ref}_{\mathrm{Ag} / \mathrm{AgCl}}$ was applied to the 
sample during 7 hours. After charging, samples were stored into liquid nitrogen in order to prevent them from hydrogen desorption at room temperature.

Mechanical tests

Tensile tests were conducted on the flat tensile specimens by using a MTS electromechanical machine outfitted with an environmental furnace. Heating was performed by using a radiation furnace at a rate of $80^{\circ} \mathrm{C} / \mathrm{min}$. Experiments were carried out at room temperature (RT), $80^{\circ} \mathrm{C}$, $150^{\circ} \mathrm{C}$ at a strain rate of $5 \times 10^{-4} \mathrm{~s}^{-1}$ and at $300^{\circ} \mathrm{C}$ for various strain rates, from $5 \times 10^{-4} \mathrm{~s}^{-1}$ to $5 \times 10^{-2} \mathrm{~s}^{-}$ 1 . Elongation of the gage length was measured by means of a laser extensometer. Tensile tests were carried out on both uncharged and hydrogen precharged samples. The HE sensitivity factor $\mathrm{I}_{\mathrm{f}}$ of each sample was obtained by measuring the relative uniform elongation loss $I_{f}=\frac{E_{0}-E_{H}}{E_{0}}$ where $\mathrm{E}_{0}$ and $\mathrm{E}_{\mathrm{H}}$ are, respectively, the uniform elongations of the uncharged and the hydrogenated tensile samples.

\section{Hydrogen content measurements}

The total amount of hydrogen introduced by cathodic charging was measured by extraction at high temperature $\left(1500^{\circ} \mathrm{C}\right)$ using a Galileo Bruker analyzer. The method consisted in melting 0.05 to $0.2 \mathrm{~g}$ samples in pure argon as a carrier gas. The amount of hydrogen was determined by using a catharometer and expressed in weight ppm. For each sample, 2 to 3 specimens were assayed.

Fracture modes characterization

Finally, rupture modes were identified by observing at different magnifications the fractured surfaces with a LEO 435VP SEM and a FEG-SEM.

Mechanical behaviour

\section{Experimental results}

The effects of hydrogen on mechanical behaviour of alloy 718 for different tensile tests temperatures are presented on Fig. 2. Whatever the temperature, strain versus stress curves ( strain rate $=5 \times 10^{-4} \mathrm{~s}^{-1}$ ) were plotted for both hydrogen precharged samples and uncharged specimens. For more clearness, only the curves obtained at RT and $300^{\circ} \mathrm{C}$ are given for the uncharged specimens in Fig. 2. At first, the results showed a significant loss of uniform elongation for all samples at low temperatures $\left(<150^{\circ} \mathrm{C}\right)$ with a $\mathrm{HE}$ sensitivity factor superior to $80 \%$ (Fig. 3). At $300^{\circ} \mathrm{C}$, a drop in uniform elongation was also observed but the hydrogen effect was less noticeable with, in this latter case, an HE sensitivity factor of only $30 \%$ (Fig. 3).Moreover, whatever the temperature, Young's modulus as well as the plastic flow rule seemed to remain unaffected by hydrogen. 


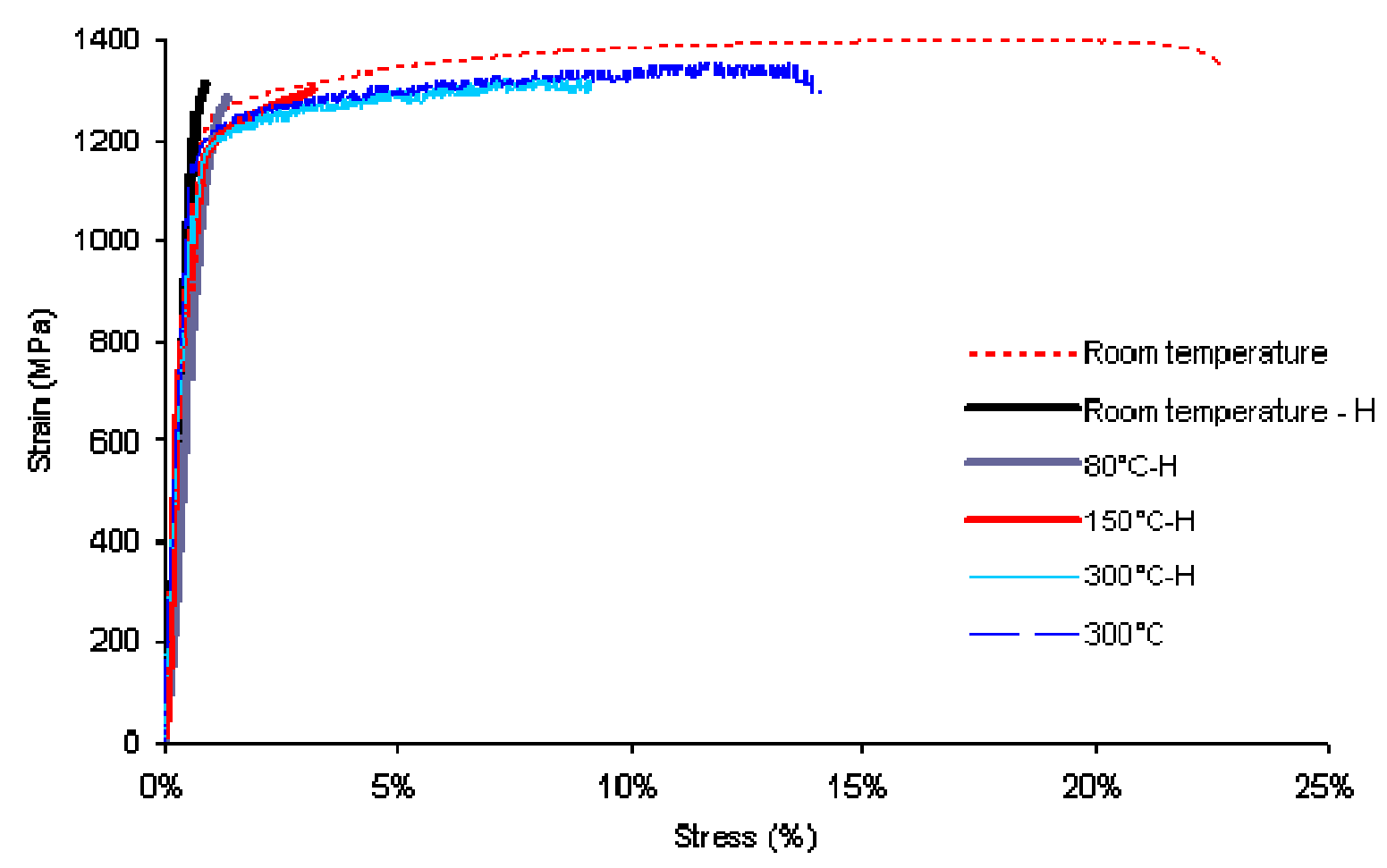

Fig. 2: Strain versus stress curves plotted for hydrogenated alloy 718 , at RT, $80^{\circ} \mathrm{C}, 150^{\circ} \mathrm{C}$ and $300^{\circ} \mathrm{C}$. Curves are also plotted for non hydrogenated alloy 718 at RT and $300^{\circ} \mathrm{C}$ for comparison. Strain rate $=5 \times 10^{-4} \mathrm{~s}^{-1}$

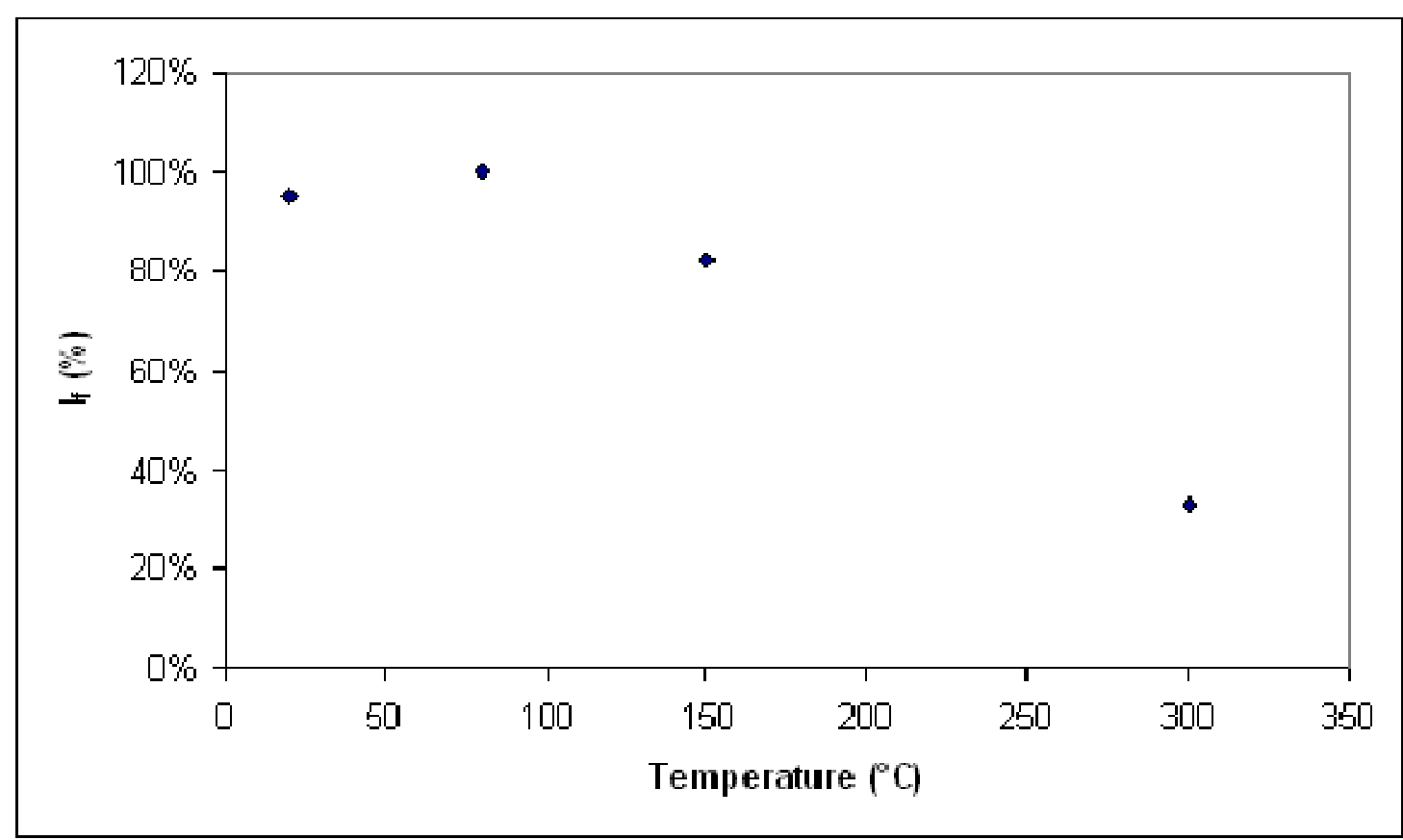

Fig. 3: Evolution of $\mathrm{HE}$ sensitivity factor $(\%)$ with temperature $\left({ }^{\circ} \mathrm{C}\right)$ - Strain rate for the tensile tests $=5 \times 10^{-4} \mathrm{~s}^{-1}$ 


\section{Rupture mode characterization}

SEM and FEG-SEM observations of the fracture surfaces after tensile tests performed for a strain rate of $5 \times 10^{-4} \mathrm{~s}^{-1}$ allowed a better understanding of the hydrogen effect. For comparison with the hydrogen precharged samples, Fig. 4 showed that the fracture modes of uncharged samples were fully ductile with dimples whatever the temperature.

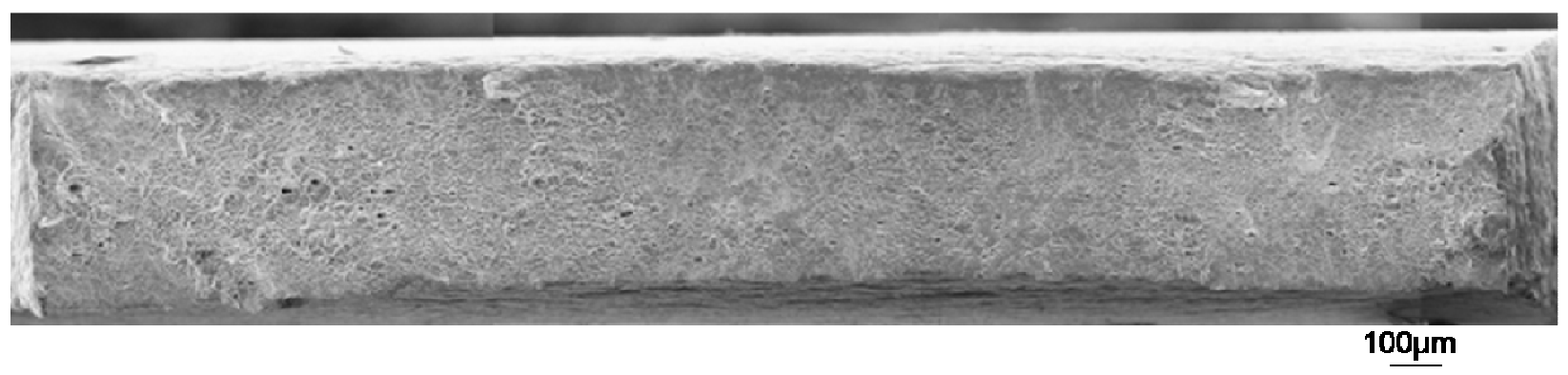

Fig. 4: Ductile fracture at $80^{\circ} \mathrm{C}$ for uncharged alloy 718

On the contrary, the fracture modes of hydrogen precharged samples were found to depend on the temperature of the tensile tests. Fig. 5 shows the different fracture modes observed for hydrogen precharged samples after tensile tests at RT, $80^{\circ} \mathrm{C}$ and $150{ }^{\circ} \mathrm{C}$. Contrary to the rupture mode observed for uncharged hydrogen samples, fracture mode was mixed:

- A brittle fracture mode (surrounded by a black line) was observed with both intergranular and transgranular (quasi-cleavage) fracture mode. The ratio of brittle transgranular fracture on intergranular fracture was qualitatively observed to increase with temperature (Fig. 6).

- A ductile area which size depended on testing temperature.

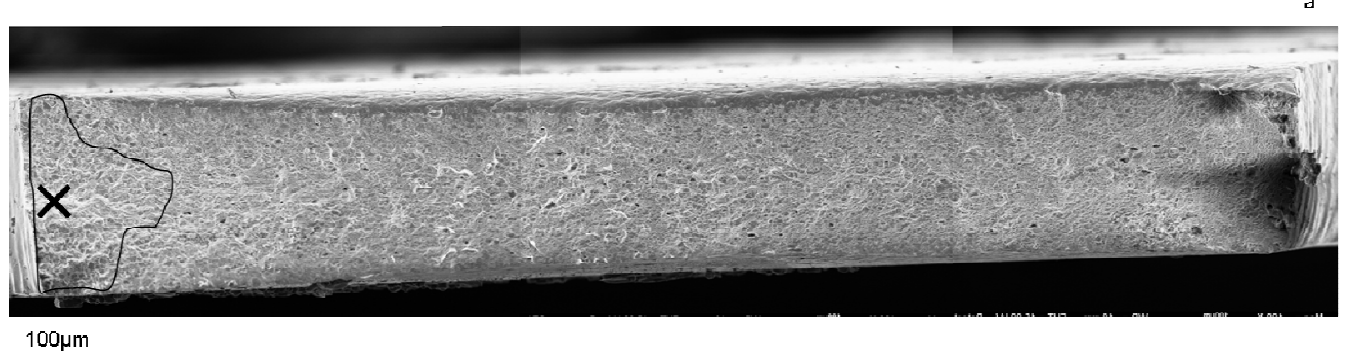

$100 \mu \mathrm{m}$
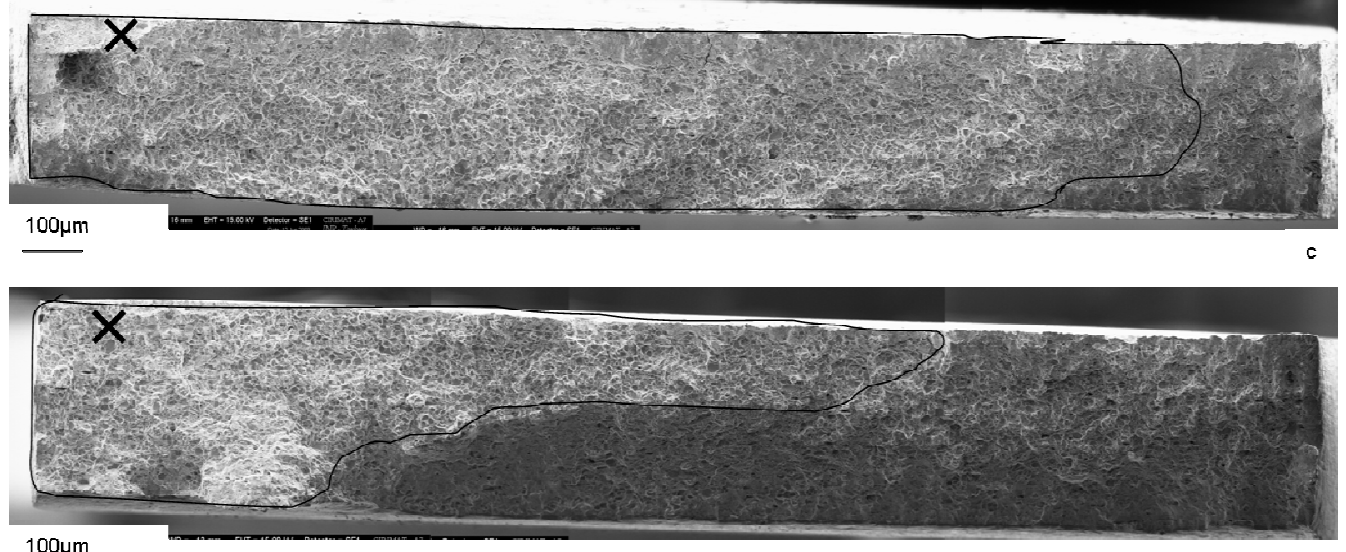

$100 \mu \mathrm{m}$

Fig. 5: Fracture surfaces of hydrogenated samples broken after tensile tests at $\mathrm{RT}(\mathrm{a}), 80^{\circ} \mathrm{C}$ (b) and $150^{\circ} \mathrm{C}(\mathrm{c})$ 


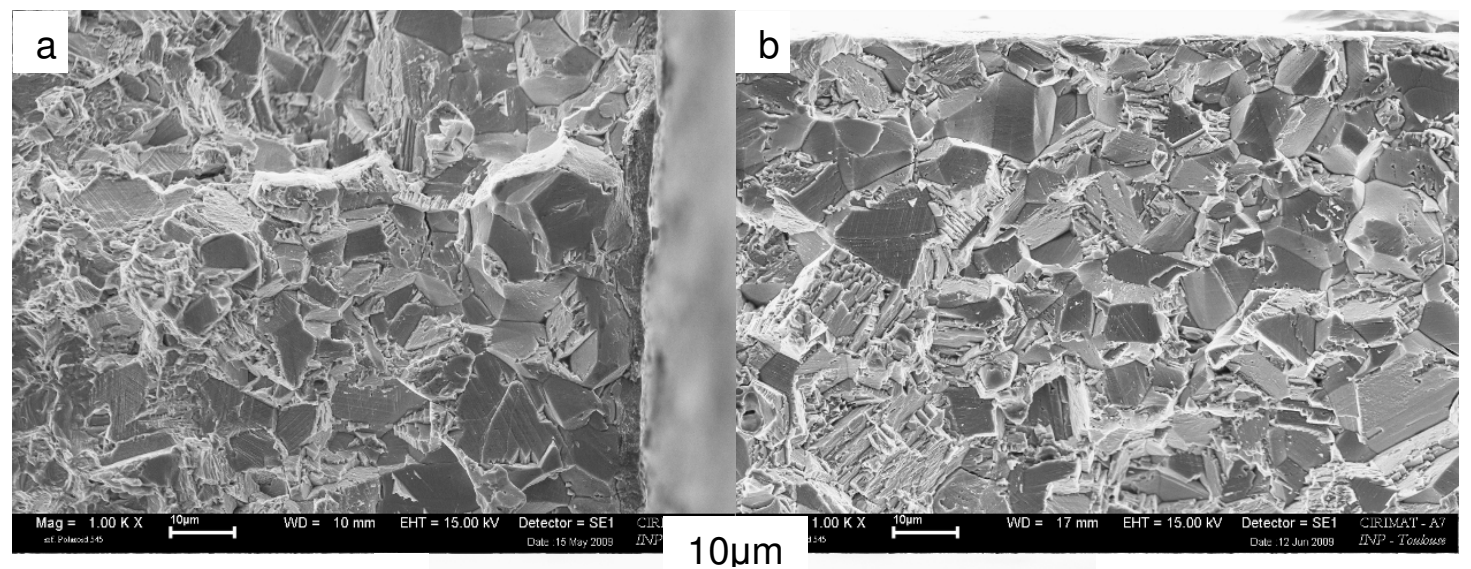

C

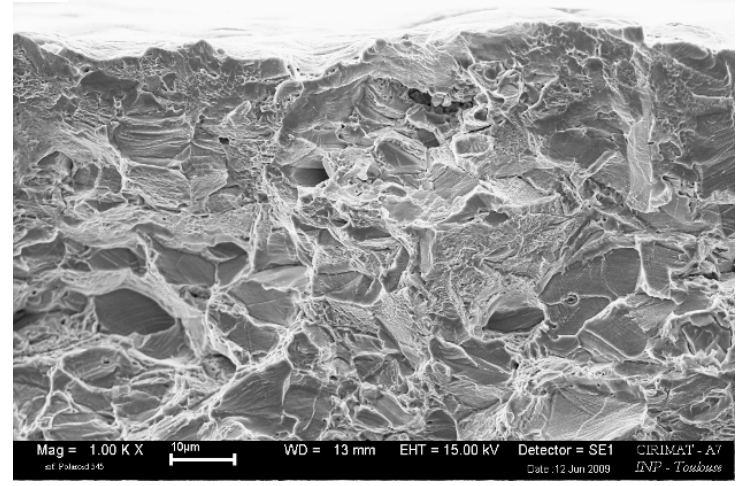

Fig. 6: Zoom on brittle fractures on hydrogenated samples after tensile tests at RT (a), $80^{\circ} \mathrm{C} \mathrm{(b)}$ and $150^{\circ} \mathrm{C}(\mathrm{c})$

However, results showed that, for tensile tests performed at $300^{\circ} \mathrm{C}$ on hydrogen precharged samples, fracture mode was ductile with dimples as for uncharged specimens. Nevertheless, it appeared that dimples were smaller for hydrogen precharged specimens than in the case of uncharged samples (Fig. 7). Dimples had an average diameter of 1 to $2 \mu \mathrm{m}$ in case of hydrogen precharged samples and $4.5 \mu \mathrm{m}$ in case of hydrogen free sample as measured by intercept method. These observations were in agreement with Wei [5] and Spilmont [6] results obtained under air at $300^{\circ} \mathrm{C}$ and $600^{\circ} \mathrm{C}[5]$ and in primary water at $300^{\circ} \mathrm{C}[6]$ respectively. 


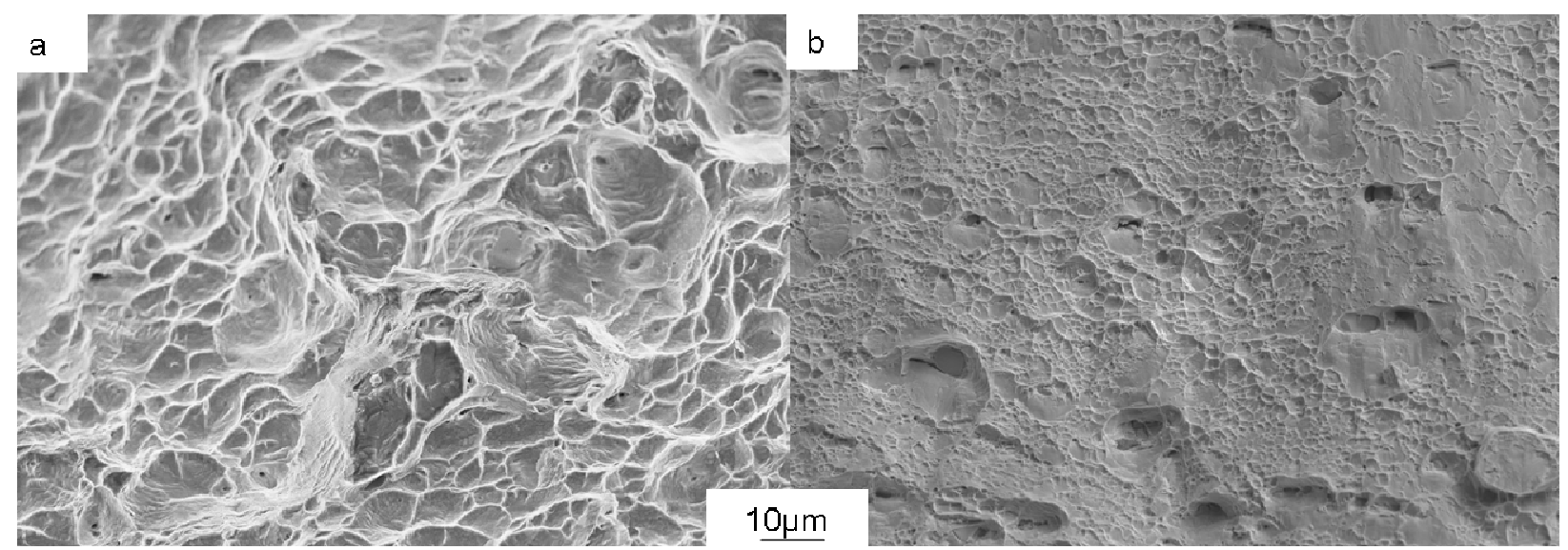

Fig. 7: Fracture mode after tensile tests at $300^{\circ} \mathrm{C}$. (a) Uncharged specimen. (b) Hydrogenated specimen

\section{$\underline{\text { H content measurements }}$}

Results of hydrogen content measurements after tensile tests (strain rate $=5 \times 10^{-4} \mathrm{~s}^{-1}$ ) at different temperatures for hydrogen precharged specimen are reported in Table 2. For comparison, hydrogen content of uncharged specimens was determined and was obviously found independent of the temperature of the tensile test.

\begin{tabular}{|c|c|}
\hline Tensile test temperature $\left({ }^{\circ} \mathrm{C}\right)$ & $\begin{array}{c}\text { Average hydrogen content after tensile test } \\
\text { (wt. ppm) }\end{array}$ \\
\hline 20 & 380 \\
80 & 330 \\
150 & 290 \\
300 & 55 \\
\hline $\begin{array}{c}\text { Uncharged specimen (whatever the } \\
\text { temperature of the tensile test) }\end{array}$ & 0.5 \\
\hline
\end{tabular}

Table 2: Evolution of the remaining hydrogen content after tensile tests at different temperatures

The results showed that the average hydrogen content measured after tensile tests decreased as the temperature of the mechanical test increased which could be explained by a phenomenon of hydrogen desorption occurring during the tensile test procedure. The desorption kinetics of reversible traps were likely to be directly related to the tensile test temperature. Indeed, the more elevated the temperature was, the more hydrogen desorption was significant during tensile test. 


\section{Discussion}

HE susceptibility of alloy 718 at RT, $80^{\circ} \mathrm{C}$ and $150^{\circ} \mathrm{C}$

At low temperature, the strong decrease of elongation of precharged samples was associated to the apparition of a mixed rupture mode and particularly to a brittle fracture mode that occurred mainly due to crack initiation and propagation. The final step of the fracture process which corresponded to crack propagation instability was clearly characteristic of a ductile fracture. The brittle fracture area was mainly intergranular with presence of transgranular (quasi-cleavage) fracture at $\mathrm{RT}$, and mainly transgranular at $80^{\circ} \mathrm{C}$ and $150^{\circ} \mathrm{C}$. These observations were in accordance with previous results obtained on aged samples of alloy 718 [1-3]. The tensile curve at RT revealed that fracture occurred with little plastic deformation. This behaviour seemed to indicate that, in this case, intergranular fracture did not need plasticity to occur. Thus, one can argue that, at this temperature, hydrogen seemed to affect the cohesion energy of the grain boundary so that a critical stress had to be reached to break the interface. In the present case, this stress was very close to the yield stress of the material. The evolution of the partitioning between intergranular and transgranular brittle fracture when temperature was increased seemed to indicate that hydrogen was partially desorbed from grain boundaries whereas hydrogen embrittlement of the $\gamma$ matrix, matrix $/ \gamma^{\prime}$ and matrix $/ \gamma$ ' interfaces remained active [3, 4]. It was worth noticing here that the hydrogen content of the samples was still very high after the tensile tests so that the reduction of the contribution of intergranular fracture could not be attributed to a decrease of hydrogen content but more likely to the reversibility of intergranular traps.

The ductile part of the fracture surfaces could be explained by an effect on strain rate on HE susceptibility of alloy 718 [1]. Indeed, during crack propagation, local strain rate increased. At high strain rate, corresponding to the final step of the fracture process, hydrogen transport by dislocation was no more possible because $\mathrm{H}$ mobility was not sufficient. Therefore hydrogen effects decreased. When temperature increased, $\mathrm{H}$ mobility was improved and it became possible for dislocations to drag hydrogen at increasing strain rates. This could explain the increase in surface area of the brittle zone at $80^{\circ} \mathrm{C}$ and $150^{\circ} \mathrm{C}$.

HE susceptibility of alloy 718 at $300^{\circ} \mathrm{C}$

At $300^{\circ} \mathrm{C}$, the mechanical behaviour of alloy 718 was less affected by hydrogen embrittlement $\left(\mathrm{I}_{\mathrm{f}}=30 \%\right)$ and fracture surface observations evidenced a ductile fracture with small dimples.

With the aim of explaining these results and observations, three possible contributions were investigated:

1. the effect of hydrogen desorption

2. the effect of the hydrogen trapping by hardening phases

3. the effect of strain rate

\section{Effect of hydrogen desorption}

$\mathrm{H}$ content measurements evidenced that the $\mathrm{H}$ content after tensile tests was divided by 5 between $150^{\circ} \mathrm{C}$ and $300^{\circ} \mathrm{C}$ (Table 2). Therefore hydrogen desorption could explain the decrease in hydrogen effect on the material and the disappearance of brittle fracture at $300^{\circ} \mathrm{C}$. In order to confirm the effect of $\mathrm{H}$ desorption, a tensile test at $80^{\circ} \mathrm{C}$ was performed after hydrogen desorption treatment at $300^{\circ} \mathrm{C}$ during 10 minutes. This duration was similar to the duration of tensile test performed at $300^{\circ} \mathrm{C}$. This treatment led to a hydrogen content of $45 \mathrm{ppm}$, which was 
similar to the value measured after tensile test at $300^{\circ} \mathrm{C}$ (Table 2). Furthermore, the specimen exposed to tensile test at $80^{\circ} \mathrm{C}$ exhibited a fracture mode with only transgranular fracture (Fig. 8a) which seemed to exhibit a ductile character with nanoscale dimples along slip plane emergences (Fig. 8b). Assuming that the hydrogen desorption treatment at $300^{\circ} \mathrm{C}$ led to $\mathrm{H}$ desorption from the GB and the matrix and that only $\mathrm{H}$ located at precipitates and carbides still remained, a ductile fracture process along slip planes using precipitates as brittle inclusions could be proposed to explain this type of ductile transgranular fracture. Inclusions were so close that dimples growing around these inclusions could coalesce very soon.

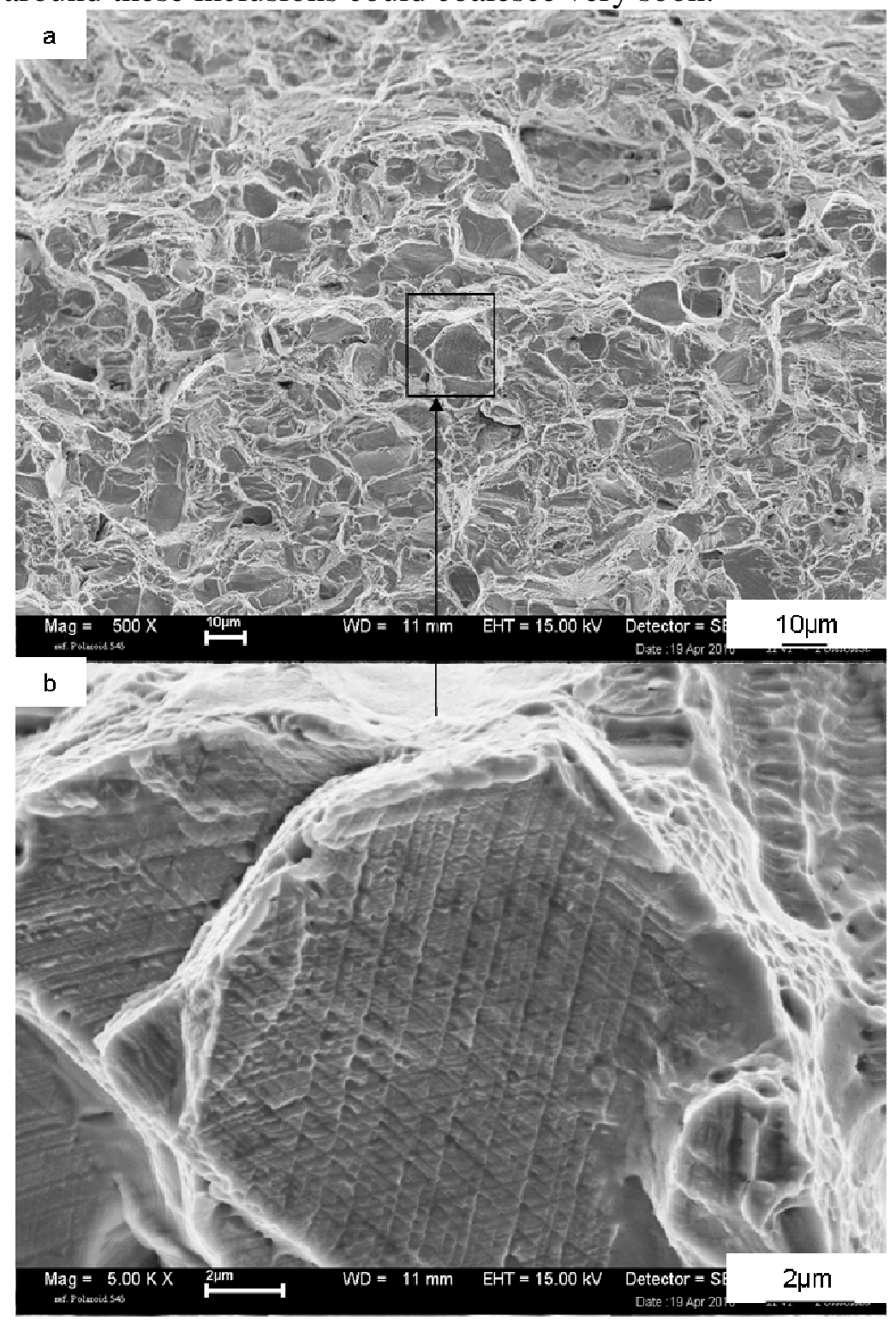

Fig. 8: Fracture surface observed on a hydrogen precharged sample after 10min. holding at $300^{\circ} \mathrm{C}$ and tensile test conducted at $80^{\circ} \mathrm{C}$

Desorption treatment thus underlined the effect of $\gamma$ " precipitates on mechanical behaviour and HE susceptibility of alloy 718 at $300^{\circ} \mathrm{C}$ and $80^{\circ} \mathrm{C}$. 
Effect of the hydrogen trapping by hardening phases

Tensile tests at $300^{\circ} \mathrm{C}$ on annealed samples (as received state) which only contained $\gamma$ matrix were performed on charged and uncharged material. Results are shown in Fig. 9. It appears that there is no effect of hydrogen on the mechanical behaviour of alloy 718 at $300^{\circ} \mathrm{C}$ in absence of $\gamma^{\prime}$ or $\gamma$ " precipitates. The fracture mode was not affected by hydrogen and remained ductile with large dimples. The results underlined the effect of transgranular precipitation on HE susceptibility of alloy 718 at high temperature.

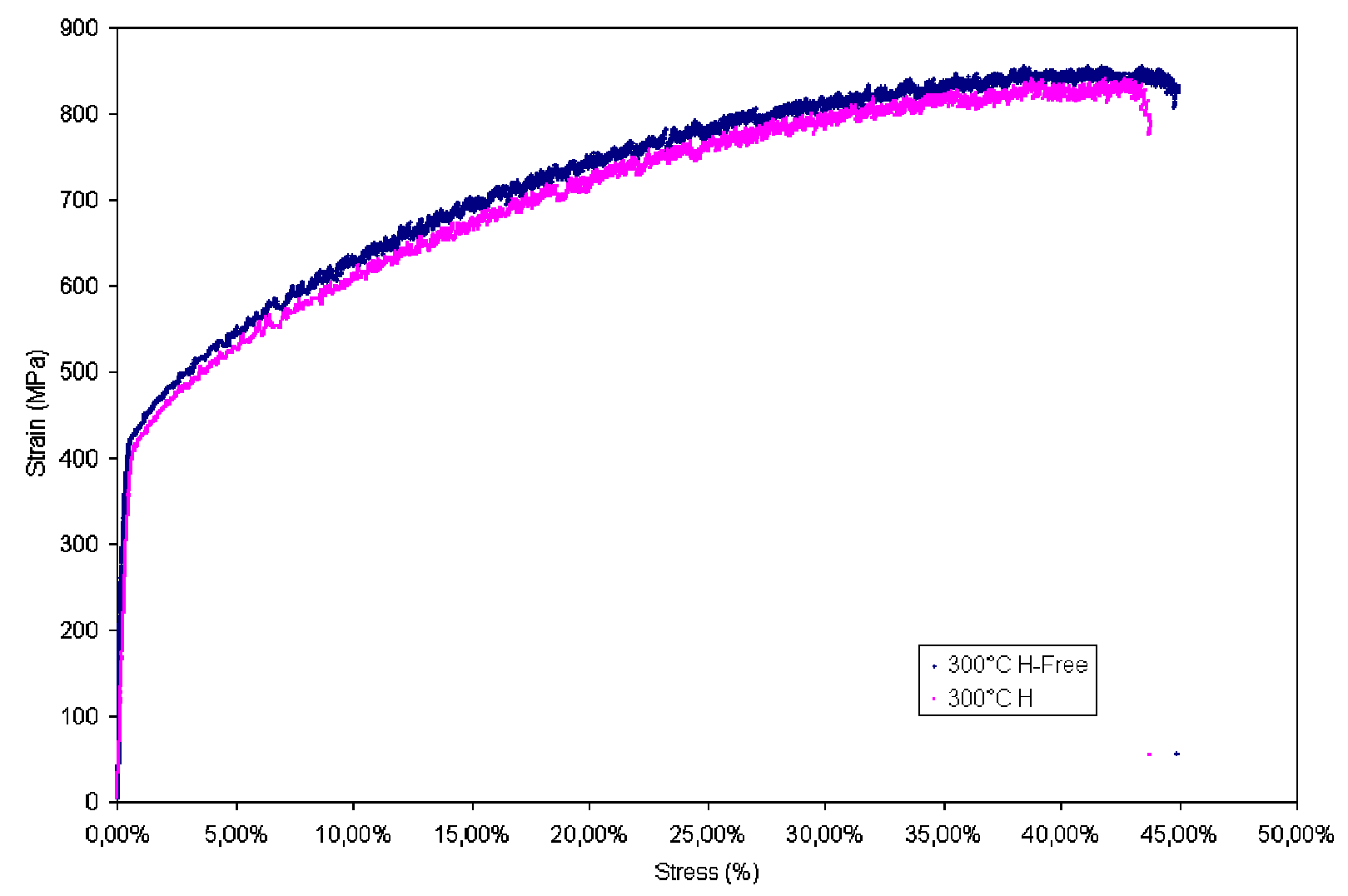

Fig. 9: Tensile test at $300^{\circ} \mathrm{C}$ on annealed alloy 718 - cathodically charged (red) and uncharged (blue) - Strain rate: $5 \times 10^{-4} \mathrm{~s}^{-1}$

\section{Effect of strain rate on $\mathrm{HE}$ at $300^{\circ} \mathrm{C}$}

Moreover, in order to assess the effect of strain rate on $\mathrm{H}$ transport by dislocations at this temperature, tensile tests were performed at $300^{\circ} \mathrm{C}$ for strain rates of $5 \times 10^{-3} \mathrm{~s}^{-1}$ and $5 \times 10^{-2} \mathrm{~s}^{-1}$ in addition to the previous test at $5 \times 10^{-4} \mathrm{~s}^{-1}$. Detailed observations of fracture surfaces revealed that the rupture was not entirely ductile but presented signs of brittleness at low magnification (Fig. 10a and b). However, at high magnification (Fig. 10c and Fig. 10d), observations revealed a "nano" ductility with nanoscale dimples -or nanovoids-, which average size ranged from 50 to 200nm (Fig. 10d). 

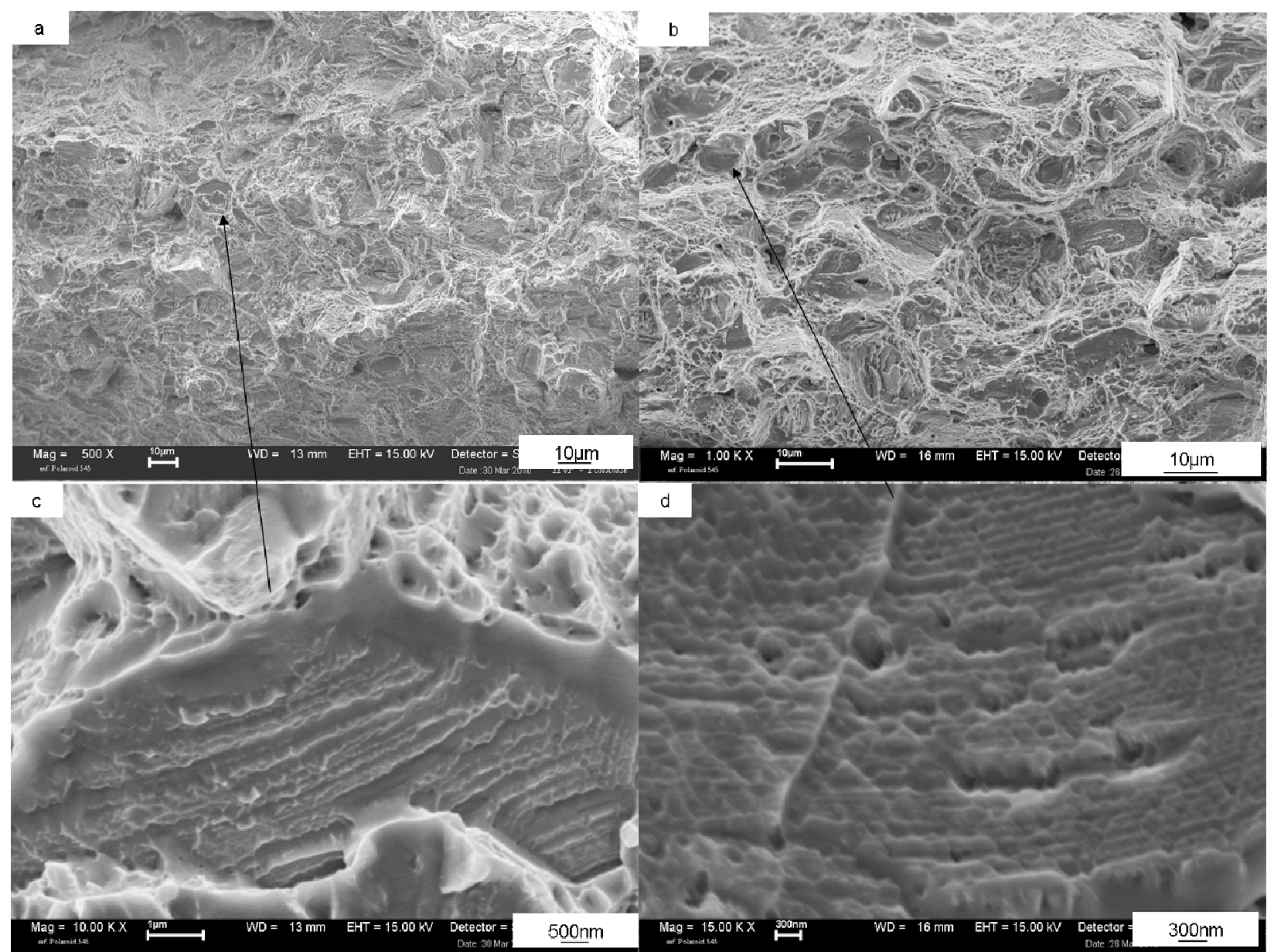

Fig. 10: fracture surfaces after tensile tests at $300^{\circ} \mathrm{C}$. Low magnification: (a) $5 \times 10^{-3} \mathrm{~s}^{-1}$, (b) $5 \times 10^{-}$ ${ }^{2} \mathrm{~s}^{-1}$. High magnification : (c) $5 \times 10^{-3} \mathrm{~s}^{-1}$, (d) $5 \times 10^{-2} \mathrm{~s}^{-1}$.

The nanoscale of the dimples could be correlated with the size of $\gamma$ ' precipitates from 40 to $60 \mathrm{~nm}$. It could be assumed that this type of fracture surfaces appeared due to the growth and the coalescence of voids from $\gamma$ ' precipitates, which were strong hydrogen traps whereas the matrix was not embrittled due to hydrogen desorption at this temperature according to previous results of this work. The amplification of this phenomenon with the increase of strain rate might be due to the increase of strain localization at high strain rates, which tended to exacerbate the role of precipitates in slip planes as inclusions for ductile fracture. In addition, this result accorded with tensile tests performed at $80^{\circ} \mathrm{C}$ after hydrogen desorption treatment at $300^{\circ} \mathrm{C}$. Indeed, in the same way, desorption treatment located hydrogen on precipitates and carbides and depleted the interfaces and the matrix in hydrogen. So far, fracture mode appeared to be transgranular. 


\section{Conclusions}

Results showed that HE susceptibility of alloy 718 was highly affected by temperature. Indeed, effects of temperature on hydrogen desorption and hydrogen-dislocations interactions were strong.

- At low temperature, hydrogen could be transported by dislocations during straining and interact with GB and precipitates. As a consequence, alloy 718 was highly sensitive to $\mathrm{HE}$ and exhibited a brittle fracture mode which was both intergranular and transgranular which suggested that GB and interfaces were the most affected hydrogen traps.

- At $300^{\circ} \mathrm{C}$, hydrogen traps such as GB were reversible contrary to hydrogen traps such as carbides and precipitates. Hydrogen transport by dislocations was not possible compared to hydrogen interstitial diffusion. Therefore alloy 718 was less sensible to HE. It presented a ductile fracture with dimples initiated on precipitates and carbides weakened because of local hydrogen enrichment. The increase of strain rates tended to exacerbate the effects of hydrogen on these traps associated to the strain localization. Tensile tests revealed a ductile fracture with nanoscale dimples.

To complete this work, the use of thermodesorption would be necessary in order to determinate desorption temperature, trapping energy and trapped hydrogen quantity of each type of trap. It also appears that the study of mechanisms of ductile fracture at $300^{\circ} \mathrm{C}$ in the case of alloy 718 must be taken into account.

\section{Acknowledgments}

Authors want to acknowledge Joel Alexis from INP-ENIT Tarbes (France) for his most valuable help in fractographic observations with FEG-SEM.

\section{References}

1. L. Fournier, D. Delafosse, and T. Magnin, "Cathodic hydrogen embrittlement in alloy 718," Materials Science \& Engineering, A269 (1999), 111-119.

2. J. He et al., "Effect of Hydrogen on deformation Structure of Inconel 718," Materials Transaction, JIM, 35 (1994), 689-694.

3. L. Liu et al., "Effect of precipitation phases on the hydrogen embrittlement sensitivity of Inconel 718," Science and Technology of advanced materials, 3 (2002), 335-344.

4. F. Galliano et al., "Effet de l'état métallurgique de l'alliage 718 sur la fragilisation par l'hydrogène," Journées Jeunes Chercheurs, Presse de l'école des Mines (2010).

5. W. Wei, "The effect of hydrogen on the high temperature mechanical properties of In 718," Superalloys 718, 625, 706 and Various Derivatives, ed. E.A. Loria (The Minerals, Metals \& Materials Society) (1997).

6. J.G. Spilmont, "Etude de la sensibilité à la fragilisation par l'hydrogène de l'alliage 718 en milieu primaire de réacteur à eau pressurisée" (Ph.D. Thesis, Ecole Nationale Supérieure des Mines de Paris, 1999), 118-131 . 
7. D. M. Symons and A. W. Thompson, "The effect of Hydrogen on the Fracture Toughness of Alloy X-750," Metallurgical and Materials Transactions A, 28A (1997), 817-823.

8. D. M. Symons, "The effect of hydrogen on the fracture toughness of alloy X-750 at elevated temperatures," Journal of nuclear materials, 265 (1999), 225-231.

9. M. Gras, "L'hydrogène dans les métaux: techniques de chargement et méthodes d'étude des effets de l'hydrogène dans les matériaux métalliques. Application au cas des aciers et des alliages de nickel," (Report EDF-DER HT-45/PV G 330-A, Electricité de France, 1988).

10. P. Lacombe, M. Aucouturier and J. Chêne, "Hydrogen embrittlement and stress corrosion cracking,” ed. R. Gibala, R.F. Hehemann (A.S.M., Metals Park) (1984).

11. J. Chêne and A.M. Brass, "Role of temperature and strain rate on the hydrogen-induced intergranular rupture in alloy 600," Metallurgical and Materials Transactions A, 35A (2004), 457-464.

12. G.A Young and J.R. Scully, "Evidence that carbides precipitation produces hydrogen traps in Ni-17Cr-8Fe Alloys," Scripta Materialia, 36 (1997), 713-719. 